\title{
The health impacts of the refugee crisis: a medical charity perspective
}

\author{
Author: Leigh Daynes ${ }^{\mathrm{A}}$
}

\begin{abstract}
Over the last year, hundreds of thousands of refugees fleeing war and persecution have travelled from the Middle East to Europe. Arduous journeys and poor living conditions are causing myriad health problems and access to basic healthcare is extremely limited for those on the move. At every stage of the journey, people are suffering, including after they settle in Europe. The difficulty in managing noncommunicable diseases means that some refugees are not getting the treatment they need, which in the long term can have a significant adverse impact on their health. Pregnant women are frequently unable to access antenatal care in Europe and the vaccination rate for refugee children is worrying low. Those who have suffered traumatic experiences in their home country are highly susceptible to developing psychological problems; an issue compounded by poverty, their displacement and being victims of violence.
\end{abstract}

KEYWORDS: Refugees, refugees crisis, migrant crisis, refugee healthcare, migrant healthcare, refugee health, migrant health

\section{Refugees and migrant health}

Over the last year, the huge movement of people from the Middle East to Europe has been well documented. A United Nations High Commissioner For Refugees (UNHCR) report, ${ }^{1}$ published at the end of 2015, found that the number of forcibly displaced people worldwide had exceeded a record 60 million, including 20.2 million refugees fleeing war and persecution. Almost five million ${ }^{2}$ people have fled from Syria since the civil war began there 5 years ago and, though the majority of them are now living in the neighbouring countries of Lebanon, Jordan and Turkey, just over 10\% have gone further afield, seeking safety in Europe.

The vast majority of refugees and migrants - both from Syria and other countries - arrive in Europe via sea. According to data from the UNHCR, ${ }^{3} 1,000,573$ migrants arrived by sea in 2015 and 34,000 by land. These crossings are often extremely perilous - almost 4,000 people lost their lives crossing the Mediterranean in 2015 - but arriving in Europe does not guarantee someone's safety or health.

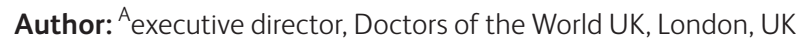

In the wake of the rise in migration, many European countries have focused their policies on minimising and containing new arrivals - seemingly forgetting, or indeed ignoring, their duty to protect and care for people.

For the hundreds of thousands of people who are travelling through Europe, access to even basic healthcare is often extremely limited. Since the crisis began, the medical charity Doctors of the World has run clinics with volunteer clinicians along the migration routes, from the Greek islands all the way to Calais, for refugees and we have seen how people's healthcare needs have changed and developed over time. Problems that our volunteer medics see range from skin and breathing problems to chronic conditions such as diabetes, pregnant women unable to access any kind of antenatal care and people who have been victims of police brutality.

\section{Direct health impact of the journey}

Irrespective of the route taken, deprivation during migration, poor living conditions and lack of adequate hygiene make refugees vulnerable to respiratory and gastrointestinal illness and skin diseases. In Calais, wounds frequently become severely infected, requiring hospital admission for surgical debridement and intravenous antibiotics. In 2015, of the 11,097 medical consultations carried out by Doctors of the World in Calais, $63 \%$ of health problems were related to living conditions in the camp and almost a quarter were orthopaedic injuries. ${ }^{4}$

According to the World Health Organization (WHO), the most common health conditions seen in refugee camps include hypothermia, burns and gastrointestinal illnesses. ${ }^{5}$ There is a high incidence of upper respiratory tract infections within the population that our medics encounter, often as a result of the damp and poor sanitary conditions, which lead to the spread of viruses and bacteria. Smoke from open fires is a risk factor for respiratory complications, lung cancer and cardiovascular disease. ${ }^{6}$ Skin conditions, including scabies, and the spread of parasites due to a lack of washing facilities and clean bedding are widely reported.

In the Doctors of the World's clinic in Larissa, one of the hottest areas of Greece, hundreds of refugees were living in extremely difficult conditions. Skin complaints were extremely prevalent (of which $40 \%$ were sunburns and insect bites), as were dehydration, otitis media and the loss of appetite across all age groups. This camp has now closed. 


\section{Non-communicable diseases}

Non-communicable diseases (NCDs) are the biggest cause of death worldwide, accounting for $63 \%$ of global deaths, including 14 million people who die before the age of 70 . $^{7}$ The prevalence of NCDs such as diabetes and hypertension in adults in certain low and middle-income countries is as high as $25-35 \%$, according to the WHO. ${ }^{8}$ For those suffering from cardiovascular disease, hypertension, diabetes, asthma and cancer, the long, arduous journeys to and through Europe frequently exacerbate these conditions, as well as causing an interruption in the continuous treatment essential for the management of NCDs.

Managing these diseases on the move is enormously challenging and sometimes people are forced to overlook the importance of seeking treatment as they must prioritise their basic needs, such as finding shelter, food and clean water.

The volunteers who worked in Doctor of the World's Idomeni clinic in northern Greece treated hundreds of people suffering from NCDs but maintaining the stocks of necessary drugs could be difficult.

If left untreated, NCDs only increase in severity, as does the risk of premature death. Chronic illnesses - such as diabetes, which is relatively easily treated with access to the right medicine - become life-threatening. For those refugees who have undiagnosed NCDs, there is also a higher risk of problems during pregnancy.

Despite literature often focusing on communicable diseases, it is in fact NCDs and an inability to tackle modifiable risk factors - resulting in increasing severity and associated complications - that increases morbidity and mortality ${ }^{9}$ for migrants and refugees. Though often seen as chronic and so not an immediate priority, not responding to NCDs in an emergency setting can have significant adverse impacts on the long-term health outcomes for refugee populations.

Prevention and early detection of NCDs are undoubtedly more cost-effective than managing the later stages of disease. ${ }^{10}$ Therefore, not addressing NCDs within the European refugee crisis is likely to come at a huge human and economic cost.

\section{Violence and brutality}

The rise of institutional and police violence has had a clear impact on the mental and physical health of refugees. Incidents of police brutality are particularly prevalent at border bottlenecks. Two areas where police violence is frequently reported are the 'Jungle' camp in Calais and, more recently, in Idomeni, which is near Greece's border with the Former Yugoslav Republic of Macedonia (FYROM) and has now been closed.

In April, the Refugee Rights Data Project (RRDP) published its findings ${ }^{11}$ regarding police brutality in Calais. Out of the 870 individuals surveyed, more than $75 \%$ had experienced police violence $-69.9 \%$ had been exposed to tear gas, while $42.4 \%$ had suffered physical violence from the police. This included cases where police violence had resulted in serious injuries, including head injuries and fractures. Fear of police violence was rated as the main reason why people did not feel safe in the camp. In 2015, Doctors of the World medics in Calais dealt with 189 cases linked to police violence. ${ }^{4}$

Tear gas can cause serious harm and respiratory difficulties, a lasting cough and chest pain with symptoms continuing for longer than 2 weeks. ${ }^{12}$ Doctors of the World has heard reports of canisters being thrown into confined spaces, including one man who said that French riot police had deployed a tear gas canister from less than a metre away from him.

In Idomeni, there were also multiple reports of refugees being injured by the FYROM police. At the beginning of April 2016, up to 300 people had to be treated ${ }^{13}$ after the security forces used tear gas, rubber bullets and stun grenades to push back refugees and migrants attempting to cross the border. Around 200 people experienced respiratory problems secondary to the tear gas and 40 others were injured by rubber bullets, including three children who sustained head injuries. Over 30 patients had to be treated for shock. The longer term psychological impact of such violence should not be understated.

The threat of violence does not only come from security forces. Human rights organisation Amnesty International ${ }^{14}$ has reported that female refugees face violence and harassment at all stages of their journeys in Europe, both from security forces and smugglers and other refugees. Refugees are also vulnerable to attacks from far-right vigilante groups. Since the beginning of 2016, there have been reports of refugees being attacked across Europe, including in France, ${ }^{15}$ Sweden ${ }^{16}$ and Germany. ${ }^{17}$

\section{Maternal and child health}

Almost $60 \%$ of refugees and migrants arriving in Greece so far this year have been women and children, with one in three migrants now classified as a minor. ${ }^{5}$ The increased presence of pregnant women, breastfeeding women and unvaccinated babies necessitates focused health interventions.

Pregnant women fleeing conflict face particular challenges in accessing antenatal care and hygienic living conditions. They commonly present with malnourishment and reproductive tract infections, making premature delivery a serious risk. ${ }^{18}$ Inadequate antenatal care is having a detrimental effect on thousands of newborns, most of whom are at risk of contracting vaccine-preventable diseases. Overcrowding in camps and immunisation gaps are causing outbreaks of diseases, including measles, croup and acute respiratory infections. ${ }^{19}$

Doctors of the World helps with child immunisation programmes in Greece and in November 2015, we won a court case forcing the French government to identify unaccompanied minors in camps and to provide more taps, toilets and rubbish collection points, meaning pregnant women and children living in the camps could have access to safe drinking water and basic sanitation.

\section{Lack of access to primary healthcare}

Refugees and migrants on the move are often reluctant to stop and actively seek out medical care, even if they desperately need it, for fear of separating from their families. However, refugees and migrants are also struggling to access primary healthcare when they settle in Europe. Data gathered from 23,040 patients at Doctors of the World clinics in 25 cities across Europe found that more than half (54.2\%) of the pregnant women surveyed had not had access to antenatal care and only one-third (34.5\%) of children seen had been vaccinated against mumps, measles and rubella and only slightly more (42.5\%) against tetanus. One in five patients had given up seeking medical care or treatment ${ }^{20}$ because of difficulties, including financial 
and language barriers, administrative problems and a lack of knowledge and understanding of their rights.

Within the UK itself, undocumented migrants are struggling to register with a GP, meaning that vulnerable people - including pregnant women, children and victims of trafficking - are being refused access to primary healthcare. During a 7-month period in 2015, Doctors of the World recorded the outcome of our attempts to register patients with NHS GPs in England, finding that $39 \%$ were wrongly refused despite being fully entitled to primary care. Fifty-five percent of patients seen at Doctors of the World's east London clinic are undocumented migrants and, on average, people have been living in the UK for 6 years before they access our services.

The 2014 Immigration Act set out the government's intention to make it "more difficult for "illegal" immigrants to live in the UK'. Since April 2015, those seeking to stay in the UK for more than 6 months must pay a healthcare surcharge of $£ 200$ per year ( $£ 150$ for students). The definition of ordinarily resident was changed meaning that all those who do not have indefinite leave to remain are now subject to charges at $150 \%$ of the NHS tariff.

The Department of Health also introduced the Migrant and Visitor NHS Cost Recovery Programme, which aims to expand charging and identify more existing chargeable patients. This has led to hospitals routinely asking about someone's immigration status before they access care and issuing more people with bills for treatment. The government is currently consulting on extending charges into primary care and accident and emergency departments.

Aside from the immediate effect these measures will have on people's mental and physical health, they will also create problems for the NHS in the long term - it is always easier and cheaper to treat an illness in its first stages than after it has developed.

Doctors of the World advocates on behalf of those who have been blocked from accessing primary healthcare and in 2015 we worked with NHS England to develop guidelines on GP registration to limit the number of those being routinely and wrongly turned away from medical surgeries every day.

\section{Mental health and psychosocial support}

Doctors of the World has found a high prevalence of mental health problems and psychological distress in migrant and refugee populations, including post-traumatic stress disorder, depression, anxiety, sleep disturbance, substance misuse and somatisation. ${ }^{6}$

Over $75 \%$ of Mediterranean Sea arrivals come from Syria, Afghanistan and Iraq, with the vast majority fleeing conflict and persecution. ${ }^{21}$ Traumatic experiences in the country of origin, compounded with displacement, loss and the unstable and unhygienic living conditions in camps, can lead to severe depression, panic attacks and debilitating forms of anxiety.

According to the German Chamber of Psychotherapists, at least half of refugees arriving in Germany suffer mental health problems related to their experiences of war and fleeing conflict. Among children, 40\% have witnessed violence and 26\% have watched family members being attacked. ${ }^{22}$ Given the scale of mental trauma among migrant populations, the significant shortage of psychotherapeutic services available to them is of major concern.
In Calais and Dunkirk, Doctors of the World has provided psychological and psychosocial support through community support groups and art therapy sessions in partnership with Art Refuge UK.

WHO projections of the prevalence of mental disorders in adult populations affected by emergencies predict that 3-4\% of people will be suffering from a severe disorder (eg psychosis, severe depression, severely disabling form of anxiety disorder) and $15-20 \%$ mild to moderate mental disorders 12 months after an emergency. ${ }^{23}$ For the Syrian Vulnerable Person Resettlement Programme alone, it is predicted that of the 20,000 refugees the $\mathrm{UK}$ has pledged to receive, there would be 60-80 people with severe mental health disorders and 300-400 with mild to moderate mental disorders arriving over the 5 -year period. Doctors of the World found that of the 23,040 patients seen at our clinics across Europe, more than $6,200(27.1 \%)^{20}$ of them perceived their mental health as bad or very bad.

\section{Conclusion}

At every stage of the journey, migration is seriously impacting the health of refugees in many ways.

Everyone has the right to appropriate medical care, regardless of their administrative or social status and governments have a duty to ensure people can access the medical help they need. All European countries must do more to provide healthcare for the refugees and migrants who arrive on their shores.

Public discourse about migration is invariably highly politicised and often negative, perpetuating a climate that harms refugees' health and wellbeing. Now more than ever, clinicians need to unite in defence of the right to provide and to receive medical care regardless of income or immigration status.

\section{Conflicts of interests}

Leigh Daynes is the executive director of the humanitarian healthcare charity, Doctors of the World, which provides medical care in more than 400 projects in 80 countries worldwide. The charity currently has medical teams in refugee camps across Europe, including in Greece and France.

\section{References}

1 United Nations Refugee Agency. Mid-year trends 2015. Geneva: UNHCR, 2015.

2 United Nations High Commissioner for Refugees. Syrian regional refugee response. Available online at http://data.unhcr.org/syrianrefugees/ regional.php [Accessed 24 June 2016].

3 Clayton J, Holland H. Over one million sea arrivals reach Europe in 2015. Lesvos: United Nations High Commissioner for Refugees, 2015. Available online at www.unhcr.org/5683d0b56.html [Accessed 24 June 2016].

4 Médecins du Monde. Programme Migrants Nord littoral Dunkerque/ Calais, Rapport D'Activities 2015.

5 World Health Organization. Refugee crisis. Situation update 3. Geneva: WHO, 2016. Available online at www.euro.who.int/_data/ assets/pdf_file/0016/305503/Refugee-Crisis-situation-updatereport-n3.pdf?ua=1 [Accessed 24 June 2016].

6 Isakjee A, Dhesi S, Davies T. An environmental health assessment of the new migrant camp in Calais. Birmingham: University of Birmingham, 2015.

7 World Health Organization. Global action plan for the prevention and control of non-communicable diseases 2013-2020. Geneva: WHO, 2013. 
8 World Health Organization. Migration and health: key issues. Available online at www.euro.who.int/en/health-topics/health-determinants/ migration-and-health/migrant-health-in-the-european-region/ migration-and-health-key-issues [Accessed 24 June 2016].

9 Yun K, Hebrank Graber LK K et al High prevalence of chronic non-communicable conditions among adult refugees: implications for practice and policy. J Community Health 2012;37:1110-8.

10 van der Wal R. Comment l'évolution des conflits implique de compter avec les maladies chroniques non transmissibles [Humanitarian intervention in a changing world: need for a new model of care]. Humanitaire Enjeux pratiques débats 2015;41:88-95

11 Refugee Rights Data Project. The Long Wait. Available online at http://refugeerights.org.uk/wp-content/uploads/2016/06/RRDP_ TheLongWait.pdf [Accessed 1 August 2016].

12 European Lung Foundation. Study finds tear gas could have temporary impact on lung health. Sheffield: ELF, 2014. Available online at www. europeanlung.org/en/news-and-events/media-centre/press-releases/ study-finds-tear-gas-could-have-temporary-impact-on-lung-health [Accessed 24 June 2016].

13 Médecins Sans Frontières. MSF treats hundreds after Greek-FYROM border violence. Geneva: MSF, 2016. Available online at www.msf.org/en/ article/20160410-msf-treats-hundreds-after-greek-fyrom-border-violence [Accessed 24 June 2016].

14 Amnesty International. Female refugees face physical assault, exploitation and sexual harassment on their journey through Europe. 2016. Available online at www.amnesty.org/en/latest/news/2016/01/ female-refugees-face-physical-assault-exploitation-and-sexualharassment-on-their-journey-through-europe/ [Accessed 24 June 2016].

15 Quine O. Calais Jungle refugees targeted by armed far-right militia in brutal campaign of violence. London: The Independent, 2016. Available online at www.independent.co.uk/news/world/europe/calais-junglerefugees-targeted-by-armed-far-right-militia-in-brutal-campaign-ofviolence-a6870816.html [Accessed 24 June 2016].
16 Desmond S. Masked men in Stockholm threaten to 'punish' refugee children. London: The Guardian, 2016. Available online at www. theguardian.com/world/2016/jan/30/masked-men-stockholmthreaten-punishment-refugee-children [Accessed 24 June 2016].

17 Borger J. German police arrest 211 after far-right riot in Leipzig. London: The Guardian, 2016. Available online at www.theguardian. com/world/2016/jan/12/german-police-arrest-211-after-far-rightriot-in-leipzig [Accessed 24 June 2016].

18 Médecins Sans Frontières. Syrian refugees in Lebanon: "Pregnant women often have no idea where to go”. Geneva: MSF, 2013. Available online at www.doctorswithoutborders.org/news-stories/field-news/ syrian-refugees-lebanon-pregnant-women-often-have-no-ideawhere-go [Accessed 24 June 2016].

19 World Health Organization. Frequently asked questions on migration and health. Geneva: WHO, 2015. Available online at www.who.int/ features/qa/88/en/ [Accessed 24 June 2016].

20 Chauvin P, Simonnot N, Vanbiervliet F, Vicart M, Vuillermoz C. Access to healthcare for people facing multiple vulnerabilities in health vulnerabilities in 26 cities across 11 countries. Paris: Doctors of the World, Médecins du Monde, 2015.

21 United Nations High Commissioner for Refugees. Refugees/migrants emergency response - Mediterranean. Available online at http://data. unhcr.org/mediterranean/regional.php [Accessed 24 June 2016].

22 AFP. Half of refugees in Germany traumatised: psychotherapists. Berlin: AFP, 2015. Available online at www.yahoo.com/news/half-refugeesgermany-traumatised-psychotherapists-144820747.html?ref=gs [Accessed 24 June 2016].

23 World Health Organization. Assessing mental health and psychosocial needs and resources: toolkit for humanitarian settings. Geneva: WHO, 2012.

Address for correspondence: Mr L Daynes, Doctors of the World UK, 29th Floor, One Canada Square, London E14 5AA, UK. Email: leigh.daynes@doctorsoftheworld.org.uk
'This landmark report lays out in the starkest terms yet the devastating impact air pollution is having on our health, our economy and our society as a whole.'

\section{Every breath we take The lifelong impact of air pollution}

This major report plainly sets out the dangerous impact that air pollution has on our nation's health. Compiled by experts in medicine and environmental sciences, the report discusses the current evidence and draws up recommendations for action.

ISBN 978-1-86016-567-2 £15 including $p+p$ or free to download

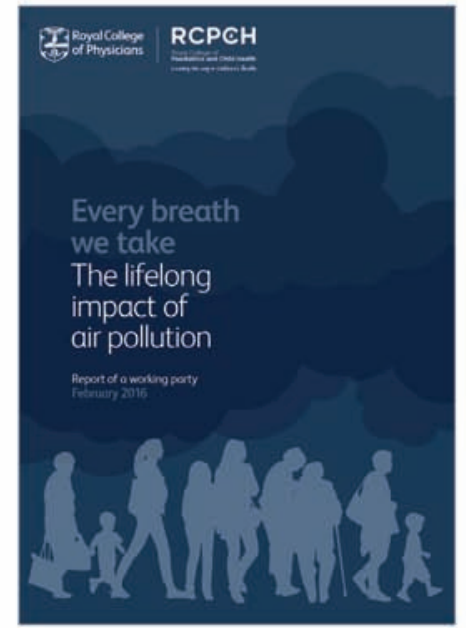

Order a copy: shop.rcplondon.ac.uk
Download the report: rcplondon.ac.uk/pollution
Royal College of Physicians 